\title{
Musculoskeletal disorders caused by physical overload: the situation in Latvia
}

\author{
J. Reste ${ }^{1,2}$, M. Eglite ${ }^{1,2}$, A. Rubine ${ }^{1}$, J. Cirule ${ }^{1,2}$, G. Zubkova $^{1}$, \\ T. Zvagule ${ }^{1,2} \&$ I. Vanadzins ${ }^{2}$ \\ ${ }^{1}$ Centre of Occupational and Radiological Medicine of Pauls Stradins \\ Clinical University Hospital, Riga, Latvia \\ ${ }^{2}$ Institute of Occupational Safety and Environmental Health, \\ Riga Stradins University, Riga, Latvia
}

\begin{abstract}
For Latvian society musculoskeletal disorders (MSDs) are becoming an urgent problem like in the majority of European countries. Physical overload is one of the most important aetiological factors for development of work-related MSDs. The aim of the study was analysis of occupational MSDs' incidence tendencies in Latvia during the time period from 1996 till 2011. Data of Latvian State Register of Occupational Diseases about incidence of occupational MSDs according to Latvian official list of occupational disorders were used. The time period between 1996 and 2011 was analysed in detail. This current paper reports a rapid increase in number of occupational MSDs revealed for the first time every year in Latvia. At the same time, a gradual decrease of "classical" occupational diseases, such as respiratory disorders caused by dust and chemical substances was observed during the period of analysis. In most cases, more than one MSD was diagnosed for one patient. The largest part of these MSDs was chronic, disabling and had been acquired for a long time before being revealed. In $94.8 \%$ of all patients with firstly revealed occupational diseases in 2011 factor physical overload (i.e. heavy lifting, repetitive or highly differentiated movements or awkward working posture, manual handling) were mentioned as harmful working risk factors. During the last ten years MSDs have taken first place in the occupational morbidity structure of Latvia. Considering the present situation in Latvia, special attention of OH\&S specialists should be paid to the early prevention of MSDs and fight against physical overload at work places. Keywords: occupational disease, musculoskeletal disorders, physical overload, work-related, morbidity, prevention, Latvia.
\end{abstract}




\section{Introduction}

Musculoskeletal disorders (MSDs) are a growing problem in majority of European countries. MSDs remain the most common occupational diseases in the European Union, and workers in all sectors and occupations can be affected.

The term "musculoskeletal disorders" denotes health problems of the locomotor apparatus, i.e. muscles, tendons, skeleton, cartilage, vascular system, ligaments and nerves. Occupational MSDs are such health disturbances which are caused by working conditions and are included in the list of occupational diseases of relevant country. Work-related MSDs include all musculoskeletal disorders that are induced or aggravated by work and the circumstances of its performance. Physical overload is one of the most important aetiological factors for the development of occupational MSDs. The risk of MSDs can increase with the pace of work, high job demands, low job satisfaction, job stress and working in cold environments. Another reason of high morbidity with MSDs disorders is the aging of population. Aging musculoskeletal system enhances the probability to get work-related MSD due to extended exposure to harmful working conditions. MSDs are the biggest cause of absence from work in the European Union - these diseases may lead to high costs for companies and the society as whole. MSDs impact on the Latvian economy is also huge resulting from reduced work productivity, increased number of patients, health-care and disability costs [1-4].

The aim of the study was exploration of occupational MSDs and its incidence tendencies in Latvia in 1996-2011 to improve early diagnosis, the initiation of treatment and rehabilitation in order to accelerate patients' return to work.

\section{Materials and methods}

The analysis of registered occupational diseases according to the data of the Latvian State Registry of Occupational Diseases run by the Centre of Occupational and Radiation Medicine of Pauls Stradins Clinical University Hospital for the time period between 1996 and 2011 was performed.

The term "occupational disease" (OD) in Latvia is defined as follows: Occupational diseases are diseases characteristic to certain categories of employees, which are caused by physical, chemical, hygienic, biological and psychological factors in the working environment. In case of suspicions occupational disorder patient is examined and sent to the Centre of Occupational and Radiation Medicine of Pauls Stradins Clinical University Hospital where the Committee on Connection of Diseases with Occupation decides if this disease fits or not with occupational disease criteria (according to Latvian legislative acts - official list of occupational diseases), registers and reports to State Labour Inspectorate about new case of occupational disease. Occupational diseases in Latvia are diagnosed and coded in accordance to the International Classification of Diseases. Currently the effective classification used in Latvia is the 43rd International Statistical Classification of Diseases and Related Health Problems (ISC-10), which is confirmed with the decree No. 20 of January 17, 1996 of the Ministry for Welfare of the Republic of Latvia. This classification has been 
adopted in Latvia without modifications, which allows for the comparison between countries.

The absolute number of patients with first time registered occupational diseases as well as the absolute number of initially registered occupational diseases was analysed. In order to characterise the rate of cases of occupational diseases in dynamics, the sickness incidence ratio was used cumulative incidence (CI). It is a quotient which is calculated according to the following equation: $\mathrm{CI}=$ the number of persons suffering from occupational diseases as a first time occurrence within 1 calendar year/100 000 of the employed in Latvia at the beginning of the year. The absolute number of new cases of occupational diseases was recalculated per 100000 employees for adequate comparison of occupational morbidity in Latvia with that of other EU Member States.

\section{Results}

Occupational morbidity in Latvia during the period from 1996 till 2011 characterizes general situation in occupational health and safety system. The number of firstly diagnosed occupational diseases and patients has gradually increased from 1996 till 2009 showing small decline for 2011. The total number of firstly diagnosed and registered occupational patients per 100000 employees has risen from 11.5 in 1996 to 140.5 in 2009 (12.2 times), as shown in figure 1. The increase in occupational morbidity is also related to the increasing number of occupational physicians.

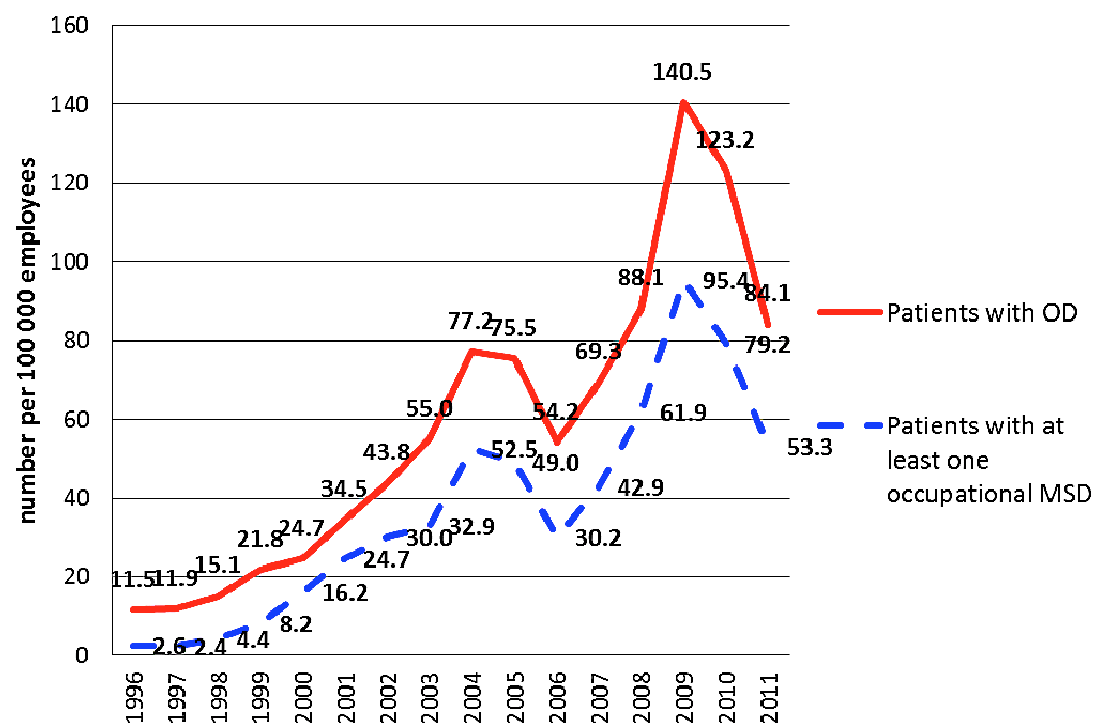

Figure 1: $\quad$ Dynamics of occupational morbidity in Latvia during 1996-2011 (total number of patients with first time registered occupational diseases and with at least one occupational MSD per 100000 employees annually). 
The decrease of occupational morbidity in 2006 and 2007 could be explained by the political decision to give examination rights back also to family doctors. It was wrong decision changed after two years in 2007 when it decided to give over rights to carry out health checks only to occupational physicians. Political decisions towards system for diagnosis and registration of occupational diseases in Latvia have been successful. Increase of registered occupational diseases is not only related to increasing number of occupational physicians but also growing awareness of employees, as well as possibility to receive compensation. State compulsory social insurance system against occupational accidents and occupational diseases was introduced in 1997. Compensation for damage incurred during work is provided from insurance premiums paid by employers (social insurance).

In Latvia quite often one person at the same time may have several occupational diseases caused by different occupational risks. For example, a builder may suffer from MSDs due to physical overload and a respiratory disease due to dust exposure, e.g.in 2011 mean number of occupational diseases per one person was 2.8. As can be seen in figure 1, the dynamics of OD incidence is very close to morbidity with occupational MSDs, which are the major part of all ODs diagnosed per year. Chronic forms of occupational diseases are most common in Latvia. On very rare occasions acute or sub-acute cases of occupational diseases or chronic occupational diseases in the initial stages have been recorded.

Similarly to situation worldwide structure of occupational diseases in Latvia has changed during 1993-2011. Since 1999 there was increase in morbidity of diseases caused by physical overloads such as musculoskeletal and connective tissue disorders as well as carpal tunnel syndrome but occurrence of occupational diseases caused by chemical substances and dust has decreased (fig. 2). As

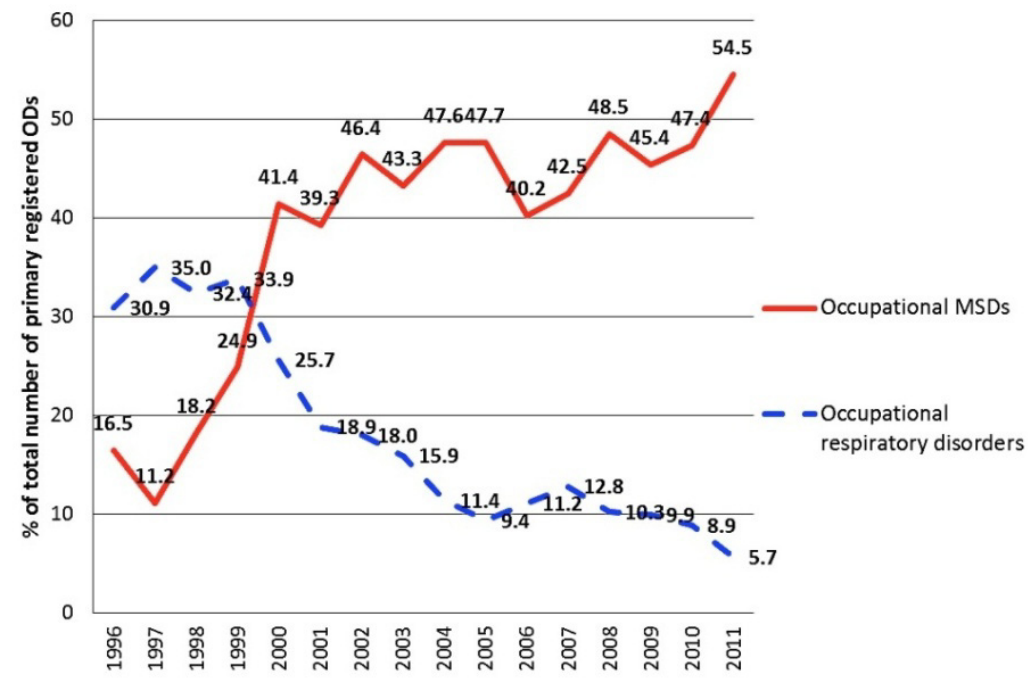

Figure 2: Percentage of occupational musculoskeletal and respiratory disorders calculated from the total number of primary registered occupational diseases per year. 
shown in figure 2 occupational MSDs in 1997 were only $11.2 \%$ of total number of ODs revealed in this year, but the part of occupational respiratory disorders was three times higher, i.e. 35\%. 14 years later, in 2011, the part of MSDs in total ODs' structure was already almost ten times higher than that of respiratory disorders, i.e. $54.5 \%$ vs. $5.7 \%$ accordingly.

In 2011 at least one occupational MSD was diagnosed in $63.3 \%$ of all patients with first time revealed occupational disease. The mean age of these patients was 54 years. Occupational MSDs were $54.5 \%$ of all occupational diseases revealed for the first time in 2011. In 94.8\% of all patients with firstly revealed occupational disease, as harmful working risk factor physical overload was mentioned (i.e. heavy lifting, repetitive or highly differentiated movements, awkward working posture, manual handling). 20\% of all firstly revealed occupational disorders in 2011 were connective tissue MSDs, such as tendinitis, bursitis, rotator cuff syndrome, etc. These disorders were localized mostly in hand and arm. 19.9\% were diseases of vertebral column and $13.2 \%$ were arthroses of different localization. In 1996 at least one MSD was diagnosed in $22.9 \%$ of all patients with first time revealed occupational disease or $16.5 \%$ of all occupational diseases firstly revealed in 1996. During explored time period in most cases more than one MSD was diagnosed in one person. Largest part of these MSDs was chronic and has been acquired long time before revealing. Ten most frequently identified occupational diseases in Latvia on 2011 are presented in the figure 3. There are connective tissue disorders (tendinitis, enthesopathy, Dupuytren's contracture, etc.), vertebral column disorders, carpal tunnel syndrome, arthrosis, vibration disease, noise induced hearing loss, upper airway disorders, ulnar nerve neuropathy, bronchial asthma and varicose veins. At least $80 \%$ of them are induced by physical overload.

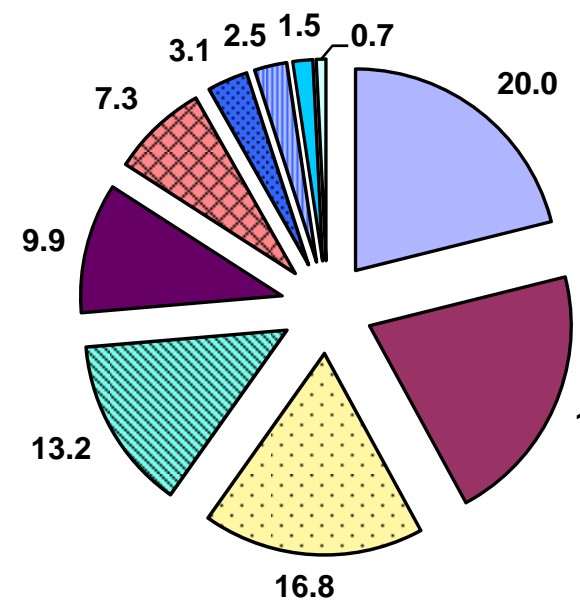

口Connective tissue disorders (tendinitis, enthesopathy, etc.)

Vertebral column disorders

口Carpal tunnel syndrome

बArthrosis

口Vibration disease

19.9

चNoise induced hearing loss

๑Upper airway disorders

ロUlnar nerve neuropathy

Figure 3: Ten most frequently identified occupational diseases in Latvia (percentage of total number of primary revealed occupational disorders in 2011). 
We have analysed also sectors of economic activity by the observed number of occupational diseases. Main sectors with the highest occupational morbidity were manufacturing; transport, storage and communication; health and social work, wholesale and retail trade, repair of motor vehicles, motorcycles and personal and household goods; construction (fig. 4).

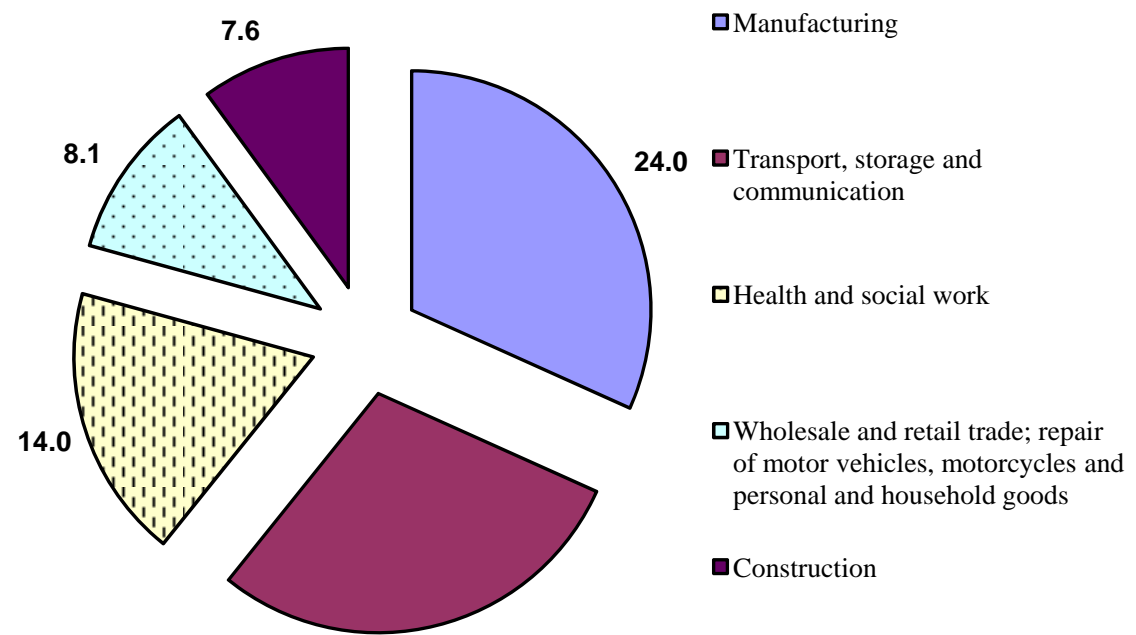

Figure 4: Five main sectors of economic activity with the highest observed occupational morbidity in 2011 (\% of total number of primary registered patients with occupational diseases).

Taking into account dramatically growing incidence of work-related MSDs in Latvia, revealing of them in late stages, high level of disability among affected persons, and highly negative economic aspect of MSDs for Latvian society in total, during the last several years special attention is paid to preventive measures. Prevention of MSDs in Latvia is becoming an urgent topic for occupational physicians, family doctors, employers, and Labour State Inspectorate.

\section{Discussion}

The number of occupational diseases and patients revealed for the first time during a year has been gradually increasing since 1993 until 2011. This is only partly related to the current working environment. Many of the currently revealed health problems are still associated with exposure to occupational risk factors during the last 10--20 years. Occupational diseases in Latvia and in other European Union countries have changed by types. At present musculoskeletal diseases are the most frequently diagnosed occupational diseases building up to approximately one half of all registered diseases. The main groups are back pain 
and work related upper limb disorders, commonly known as "repetitive strain injuries” [3, 5, 6]. Lifting, poor postures and repetitive movements are among the causes and some types of disorders are associated with particular tasks or occupations. Beside the effects on workers themselves MSDs may lead to high costs to companies and the society as a whole. MSDs are also one of the most important causes of long-term sickness absences. They are a significant ill health and cost problem and are on the increase $[2,4]$. Treatment and recovery are often unsatisfactory especially for most of chronic causes. It is therefore necessary to detect the early stages of the MSD. It is important to consider ways to reduce the incidence of occupational MSDs.

The world's scientists agree that many physical exertions caused by MSD are controlled with preventive measures. They can be divided into several groups: law, technology development, ergonomics, information and education, employee monitoring and health care as well as scientific research. One way forward is to improve quality of mandatory health checks and improve diagnostics of occupational diseases. Occupational physicians have become more popular in Latvia enhancing cooperation with employers, employees and other practitioners. This has resulted in decreased number of companies in which employees have not mademandatory health checks (MHC). If in 2005 and 2006 years health checks were not provided in about $50 \%$ of the companies, then the last three years - in about $15 \%$ of the companies. According to results of MHC, occupational physician can give some advices for employer for safer work conditions. Occupational physician can visit work place and evaluate working conditions of employee, who was sent for MHC, and examines employees estimating probable occupational diseases [7].

Are there a sufficient number of Latvian occupational physicians and do they have appropriate qualifications to perform these tasks? Data from the Registry of Latvian Occupational Physicians reveal that the number of physicians has grown by years:

1994 - 35 physicians,

2000 - 314 physicians,

2010 - 449 physicians,

$2012-455$ physicians.

There were very few occupational physicians in 1994 - only 35. The decision was made to: reorganise training process and create sufficient pool of physicians to provide health examinations and diagnostics of occupational diseases for all Latvia; re-train so called "shop physicians" working in in-house units of large companies (starting 1994). The number of occupational physicians in 18 years has increased 12.3 times. At present in Latvia is one occupational physician for about 1,800 employees.

A new training system for occupational physicians was created. There are two ways to get a certificate of occupational physician: residency - four years; updating course for physicians already working - 500 hours (one year). Training is provided by the Department of Occupational and Environmental Medicine and IOSH of Riga Stradins University; Association of Latvian Occupational Physicians; invited external specialists (insurance, infectology, personal protective equipment, etc.) [7]. 
Need to improve communication and coordination among occupational physicians, family doctors and employers about MSDs treatment and occupational rehabilitation to treat when another can be treated as late treatment affects the severity of the individual's ability to maintain a job.

\section{Conclusions}

1. The number of occupational diseases and patients revealed annually for the first time has been gradually increasing. An increase of registered occupational diseases is also related to growing awareness of employees, increasing number of occupational physicians, as well as the possibility to receive financial compensation.

2. Since 1999 there has been an increase in morbidity of diseases caused by physical overload, such as musculoskeletal and connective tissue disorders, as well as carpal tunnel syndrome, but the occurrence of occupational diseases caused by chemical substances and dust has decreased.

3. Occupational MSDs were $54.5 \%$ of all occupational diseases revealed for the first time in 2011 . In $94.8 \%$ of all patients with a firstly revealed occupational disease, as harmful working risk factor physical overload was mentioned (i.e. heavy lifting, repetitive or highly differentiated movements or awkward working posture, manual handling).

4. The Latvian policy makers are encouraging early diagnosis, treatment and rehabilitation occupational MSDs. The number of certified occupational physicians has increased in the last 18-year period as well as the number of compulsory health examinations being carried out has increased.

\section{References}

[1] Ariëns, G., van Mechelen, W., Bongers, P. M., Beriter, L.M. and Wal, G., Physical risk factors for neck pain. Scandinavian Journal of Work, Environment \& Health, 26(1), pp. 7-19, 2000.

[2] Bos, E., Krol, B., van der Star, L. and Groothoff, J., Risk factors and musculoskeletal complaints in non-specialized nurses, IC nurses, operation room nurses, and X-ray technologists. International Archives of Occupational and Environmental Health, 80(3), pp. 198-206, 2007.

[3] Hayes, M., Cockrell, D. and Smith, D.R., A systematic review of musculoskeletal disorders among dental professionals. International Journal of Dental Hygiene, 7(3), pp. 159-65, 2009.

[4] Miranda, H., Kaila-Kangas, L., Heliövaara, M., Leino-Arjas, P., Haukka, E., Liira, J. and Viikari-Juntura, E., Musculoskeletal pain at multiple sites and its effects on work ability in a general working population. Occupational and Environmental Medicine, 3, pp. 12-19, 2009.

[5] Information notices on occupational diseases: a guide to diagnosis; Office for Official Publications of the European Communities, Luxembourg, p.276, 
2009, online. http://bookshop.europa.eu/is-bin/INTERSHOP.enfinity/WFS/ EU-Bookshop-Site/en_GB/-/EUR/ViewPublication-Start?PublicationKey= KE8009534 [viewed 15.12.2012.].

[6] Kaergaard, A. and Andersen, J. H., Musculoskeletal disorders of the neck and shoulders in female sewing machine operators: prevalence, incidence, and prognosis. Occupational and Environmental Medicine, 57(8), pp. 528534, 2000.

[7] Eglite, M., Vanadzins, I., Feldberga, I. and Usacka, I., Development of Latvian society of occupational physicians and its influence on occupational safety and health system in Latvia. Materials of the Conference on occupational health and safety: From policies to practice, eds. I. Vanadzins, I. Martinsone, L. Skreitule, RSU: Riga, p.19, 2012. 